\title{
Hypertensive Encephalopathy
}

National Cancer Institute

\section{Source}

National Cancer Institute. Hypertensive Encephalopathy. NCI Thesaurus. Code C3503.

Encephalopathy resulting from hypertension. 